13

\title{
Формирование упорядоченных кремниевых структур на поверхности графита
}

\author{
(C) А.А. Ревегук, А.Е. Петухов, А.А. Вишнякова, А.В. Королева, Д.А. Пудиков, Е.В. Жижин \\ Санкт-Петербургский государственный университет, \\ Санкт-Петербург, Россия \\ E-mail: anastacia.aizenstein@gmail.com
}

Поступила в Редакцию 2 апреля 2019 г.

В окончательной редакции 2 апреля 2019 г.

Принята к публикации 2 апреля 2019 г.

Исследовалась возможность формирования упорядоченных кремниевых структур, в том числе силицена, на поверхности графитовых подложек. Также изучалось влияние различных условий осаждения атомов кремния на конечную структуру. Информация о морфологии поверхности была получена техникой атомносиловой микроскопии, а электронная структура измерялась методом Оже-электронной спектроскопии.

Ключевые слова: силицен, графит, ОЭС, АСМ.

DOI: 10.21883/FTT.2019.08.47984.443

\section{1. Введение}

В связи с непрекращающейся тенденцией к уменьшению размеров и повышению энергоэффективности электрических компонентов, с появлением и развитием наноэлектроники, кремниевые структуры продолжают вызывать интерес научного сообщества во всем мире. При этом в последнее десятилетие, в связи с открытием графена, также большую заинтересованность вызывают двумерные наноструктуры из-за их особых электрических свойств, позволяющих их широкое использование в наноэлектронике. В частности, наиважнейшим таким свойством являются особенности электронных состояний на уровне Ферми в области точки $K$ зоны Бриллюэна: в ее окрестности дисперсионная зависимость $\pi$-состояния графена имеет линейный характер (конус Дирака) [1-4]. Однако, на данный момент использование графена в наноэлектронике затруднено в связи как с отсутствием достаточно эффективных и экономически выгодных способов синтеза [5-6], так и вследствие различных факторов, связанных с влиянием подложек и дефектов на электронные свойства графена.

Одним из альтернативных направлений исследований в настоящее время является подбор другого, аналогичного графену по электронной структуре, двумерного материала. Доказано, что особые электронные свойства, характерные для графена, могут распространяться также и на другие аналогичные двумерные структуры, например, состоящие из атомов кремния - силицен [7,8]. Учитывая, что на данный момент кремний активно используется в индустрии микроэлектроники, производство кремниевых структур выглядит наиболее рентабельным и простым в реализации.

На сегодняшний момент проведен ряд исследований кремниевых структур, близких к двумерным. После публикации работ, посвященных эпитаксиальному росту кремния на различных подложках [9-12], исследователями был проведен ряд экспериментов по синтезу силицена на серебряных подложках, была показана его кристаллическая и электронная структура на серебре и золоте $[13,14]$, была изучена стабильность структуры [15]. В 2016 г. была опубликована статья, описывающая процесс синтеза силицена на подложке высокоориентированного пиролитического графита (HOPG) [16].

Простота и низкая стоимость синтеза силицена на HOPG, описанная в статье [16], является исключительно значимым фактором для дальнейшего использования силицена в наноэлектрической промышленности, поэтому изучение возможностей, достигаемых с помощью вариации условий синтеза силицена на графитовых подложках, является на данный момент актуальной задачей. Таким образом, целью данной работы было исследование формирования кремниевых структур на графитовых подложках (монокристаллический графит и HOPG) при различных условиях синтеза.

\section{2. Экспериментальные детали}

Исследования проводились на модуле зондовой микроскопии научно-исследовательской платформы Нанолаб ресурсного центра „Физические методы исследования поверхности“ Научного парка и на сканирующем зондовом микроскопе Solver Pro-M лаборатории физической электроники кафедры Электроники твердого тела Санкт-Петербургского государственного университета. Электронная структура измерялась методом Оже-электронной спектроскопии (ОЭС). Информация о кристаллической структуре была получена с помощью дифракции медленных электронов (ДМЭ). Измерения проводились при комнатной температуре. Базовое давление в вакуумной камере во время эксперимента не превышало $2 \cdot 10^{-10}$ mbar. 
Для получения информации о морфологии поверхности была использована техника атомно-силовой микроскопии (АСM) в полуконтактном режиме. После синтеза каждого образца и проведения соответствующих ОЭС-измерений, образцы извлекались из вакуумной камеры и помещались в модуль сканирующего зондового микроскопа Solver PRO-М для проведения ACM-измерений. Для записи изображений использовались кремниевые кантилеверы NSG 10. Обработка экспериментальных данных проводилась в программе Image Analysis. Численный анализ ACM-изображений, включая оценку доли площади поверхности, занимаемой кремнием, производился с помощью опорной кривой Аббота-Файрстоуна [17]. Размер погрешностей (учитывающий разрешение АСМ-изображения и среднеквадратичное отклонение) для ширины линий составлял не более $25 \%$, для всех остальных величин - не более $15 \%$.

В качестве подложек использовались высокоориентированный пиролитический графит (HOPG) и монокристалл графита. Подложки были закреплены на держателе из нержавеющей стали, верхние слои подложек были сколоты с помощью медного скотча. Непосредственно перед синтезом проводилась процедура дегазации в сверхвысоком вакууме при $500^{\circ} \mathrm{C}$ (нагрев производился до давления в вакуумной камере лучше чем $\left.5 \cdot 10^{-9} \mathrm{mbar}\right)$. Чистота поверхности контролировалась с помощью ОЭС и ДМЭ (рис. 1). На чистую поверхность подложки производилось напыление кремния.
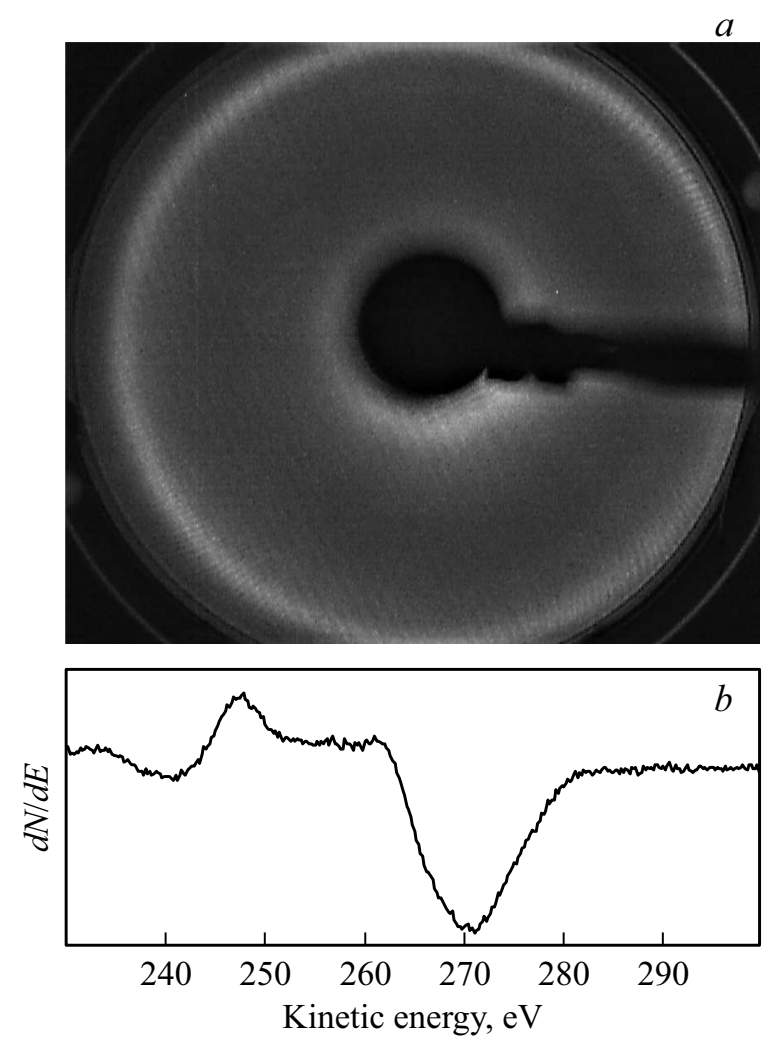

Рис. 1. $a-$ изображение ДМЭ HOPG, $b-$ Оже-электронный спектр HOPG.
Таблица 1. Условия синтеза образцов

\begin{tabular}{c|c|c|c|c}
\hline $\begin{array}{c}\text { № } \\
\text { образца }\end{array}$ & Подложка & $\begin{array}{c}\text { Скорость } \\
\text { напыления, } \\
\AA / \mathrm{min}\end{array}$ & $\begin{array}{c}\text { Толщина } \\
\text { слоя, } \\
\mathrm{ML}\end{array}$ & $\begin{array}{c}\text { Температуре } \\
\text { подложки, } \\
{ }^{\circ} \mathrm{C}\end{array}$ \\
\hline 1 & HOPG & $0.155 \pm 0.005$ & 0.75 & $\begin{array}{c}20 \\
\text { (комнатная) }\end{array}$ \\
\hline 2 & Графит & $0.155 \pm 0.005$ & 0.75 & $\begin{array}{c}20 \\
\text { (комнатная) }\end{array}$ \\
\hline 3 & НОРG & $0.24 \pm 0.01$ & 1.5 & $\begin{array}{c}20 \\
\text { (комнатная) }\end{array}$ \\
\hline 4 & HOPG & $0.24 \pm 0.01$ & 1.5 & 210
\end{tabular}

Источник кремния представлял собой тонкую пластину $\mathrm{Si}$, закрепленную на танталовых держателях, подключенных к электрическим вводам. Напыление было реализовано путем пропускания тока через пластину. Скорость напыления оценивалась по кварцевым микровесам и составляла от 0.155 до $0.24 \AA / \min$ для разных образцов.

Были подготовлены 4 образца (см табл. 1).

\section{3. Результаты и обсуждение}

\section{1. Оже-спектроскопия}

Оже-электронные спектры Si LVV и C KLL для всех образцов представлены на рис. 2. Характерными особенностями спектров, представленных на рисунке, являются Оже-пики C KLL $(270 \mathrm{eV})$ и $\mathrm{Si} \operatorname{LVV}(90.5 \mathrm{eV})$.

Значение кинетической энергии для характерной особенности и форма Оже-спектров (рис. 2, $a, b)$ соответствует эталонным спектрам для кремния и графита [18], что свидетельствует об отсутствии взаимодействия между адсорбированными атомами кремния и нижележащей графитовой подложкой, а также посторонних примесей, в частности, кислорода. После каждого напыления атомов кремния на подложки регистрировался контрольный Оже-электронный спектр в диапазоне энергий линии O KLL, который подтверждал полное отсутствие примеси.

Рассмотрим более детально изменение интенсивности Оже-спектров для разных образцов. На рис. 2, $b$ приведены спектры после напыления $0.75 \mathrm{ML}$ (спектр 1) и $1.5 \mathrm{ML}$ (спектр 3) атомов кремния на подложку HOPG при комнатной температуре. Увеличение количества напыляемого кремния приводит к пропорциональному изменению интенсивности Оже-спектров Si LVV. При этом интенсивность соответствующих Оже-спектров C KLL и положение по кинетической энергии характерной особенности остается неизменным (рис. 2, $a$, спектр 1,3). На рис. 2,b (спектр 4) приведен Оже-спектр после напыления $1.5 \mathrm{ML}$ атомов кремния на подложку HOPG 


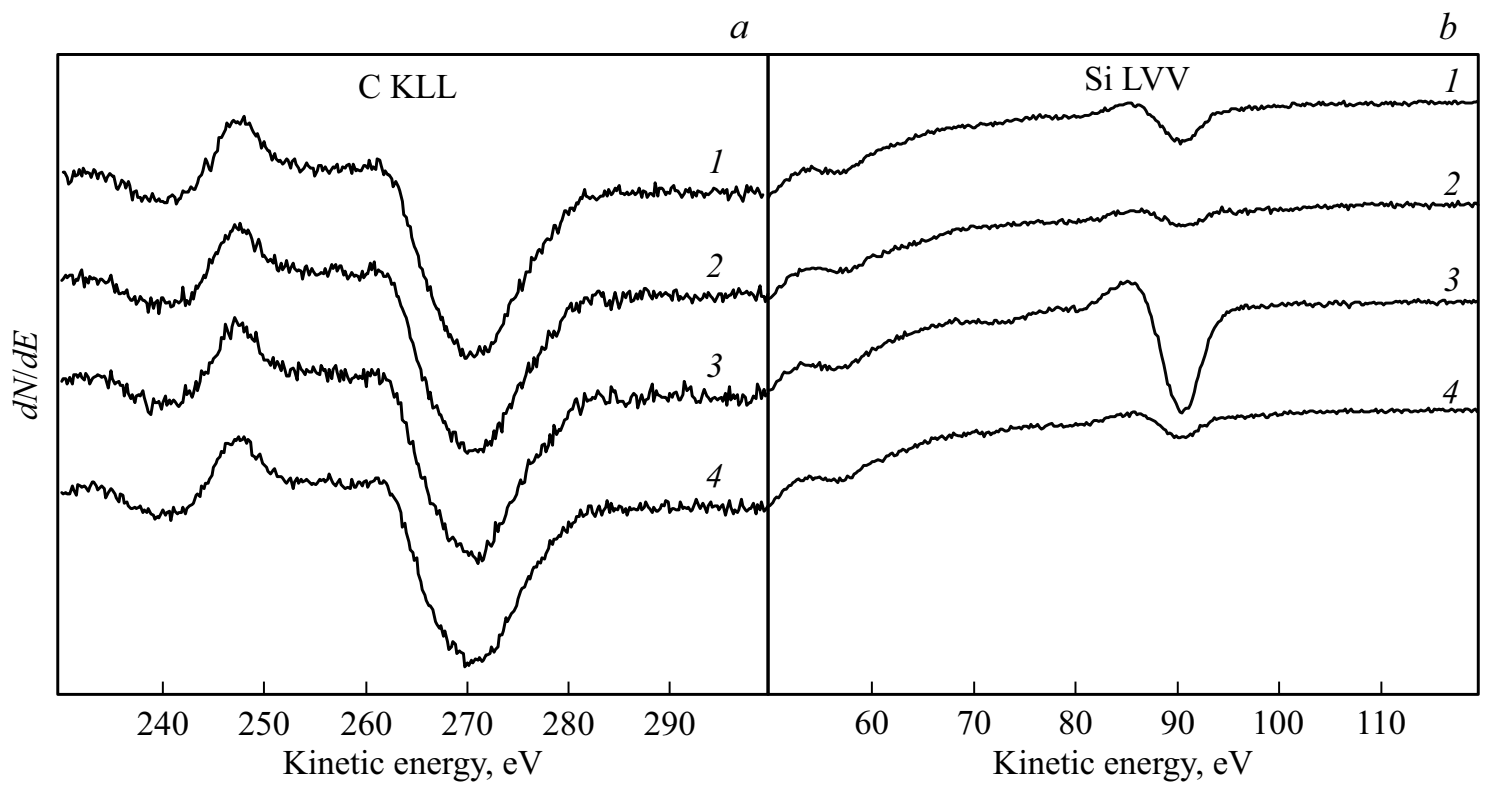

Рис. 2. $a$ - Оже-электронные спектры C KLL для образцов с 1 по $4, b$ - Оже-электронные спектры Si LVV для образцов с 1 по 4 .
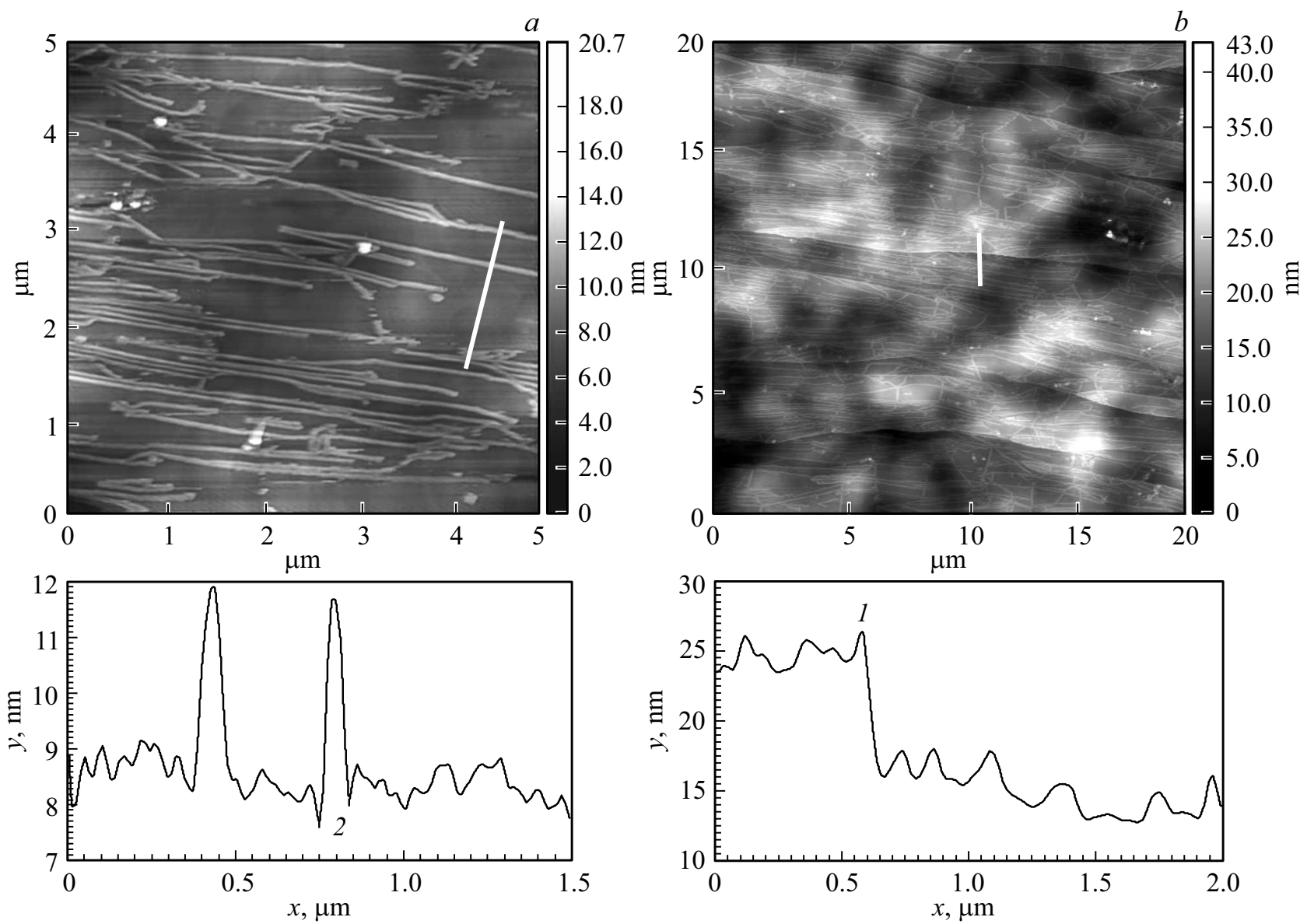

Рис. 3. $a$ - АСМ-изображение образца № $1,5 \times 5 \mu \mathrm{m}$, ниже - сечение АСМ-изображения; $b$ - АСМ-изображение образца № 1 , $20 \times 20 \mu \mathrm{m}$, ниже - сечение ACМ-изображения. Цифры 1 и 2 указывают на кремниевые структуры на границе террас HOPG и на гладкой поверхности соответственно. Белой линией указаны направления сечения. 
при температуре подложки $210^{\circ} \mathrm{C}$. Интенсивность Ожеспектра $\mathrm{Si}$ (LVV) значительно меньше, чем при комнатной температуре (рис. 2, $b$, спектр 3 ) и химический сдвиг не формируется. Этот факт свидетельствует о том, что при напылении на нагретую подложку часть атомов кремния десорбируется с поверхности или растворяется в объеме подложки на глубине, превышающей длину свободного пробега Оже-электронов (5-10 ML) [19].

Синтез на подложке монокристаллического графита (образец 2) приводит к уменьшению интенсивности спектра Si LVV по сравнению с подложкой HOPG (образец 1) при тех же параметрах (рис. 2, $b$, спектры 1 и 2). Различие в интенсивности Оже-пиков связано с наличием значительной фрагментированности поверхности подложки монокристаллического графита (рис. 4).

\section{2. Атомно-силовая микроскопия}

На АСМ-изображениях всех образцов кремниевая структура на поверхности представляет собой множественные линии высотой от 8 до $11 \mathrm{ML}$, монослойных структур не наблюдается (табл. 2). Согласно работе [15], силицен является относительно нестабильной кристаллической структурой, поскольку кремний на поверхности имеет тенденцию коалесцировать в более стабильную структуру с $s p^{3}$-гибридизированными орбиталями атомов кремния.

На рис. 3 изображен рельеф поверхности образца № 1. Линии кремния на поверхности HOPG ориентированы преимущественно в одну сторону (скорее всего, это направление связано со структурой подложки на рис. $3, b$ видно, что направление линий кремния перпендикулярно направлению скола подложки, то есть параллельно преимущественному направлению границ террас). На рис. 3 изображены характерные примеры сечений поверхности образца. Цифрой 1 обозначено сечение кремниевой линии, локализованной на физической особенности поверхности (краю террасы). Цифрой 2 указана линия, расположенная на гладкой части HOPG, на поверхности одной террасы. Наличие линий как на краю террасы, так и на ее поверхности говорит о том, что, хоть особенности рассматриваемой кремниевой

Таблица 2. Параметры кремниевых структур, полученные из данных АCM

\begin{tabular}{c|c|c|c|c}
\hline $\begin{array}{c}\text { № } \\
\text { образца }\end{array}$ & $\begin{array}{c}\text { Средняя } \\
\text { высота, ML }\end{array}$ & $\begin{array}{c}\text { Средняя } \\
\text { высота, nm }\end{array}$ & $\begin{array}{c}\text { Средняя } \\
\text { ширина, nm }\end{array}$ & $\begin{array}{c}\text { Площадь } \\
\text { покрытия, \% }\end{array}$ \\
\hline 1 & 8.4 & 2.1 & 60 & 15 \\
\hline 2 & 8.8 & 2.2 & 90 & 22 \\
\hline 3 & 11.2 & 2.8 & 80 & 33 \\
\hline 4 & 11.6 & 2.9 & 50 & 20
\end{tabular}
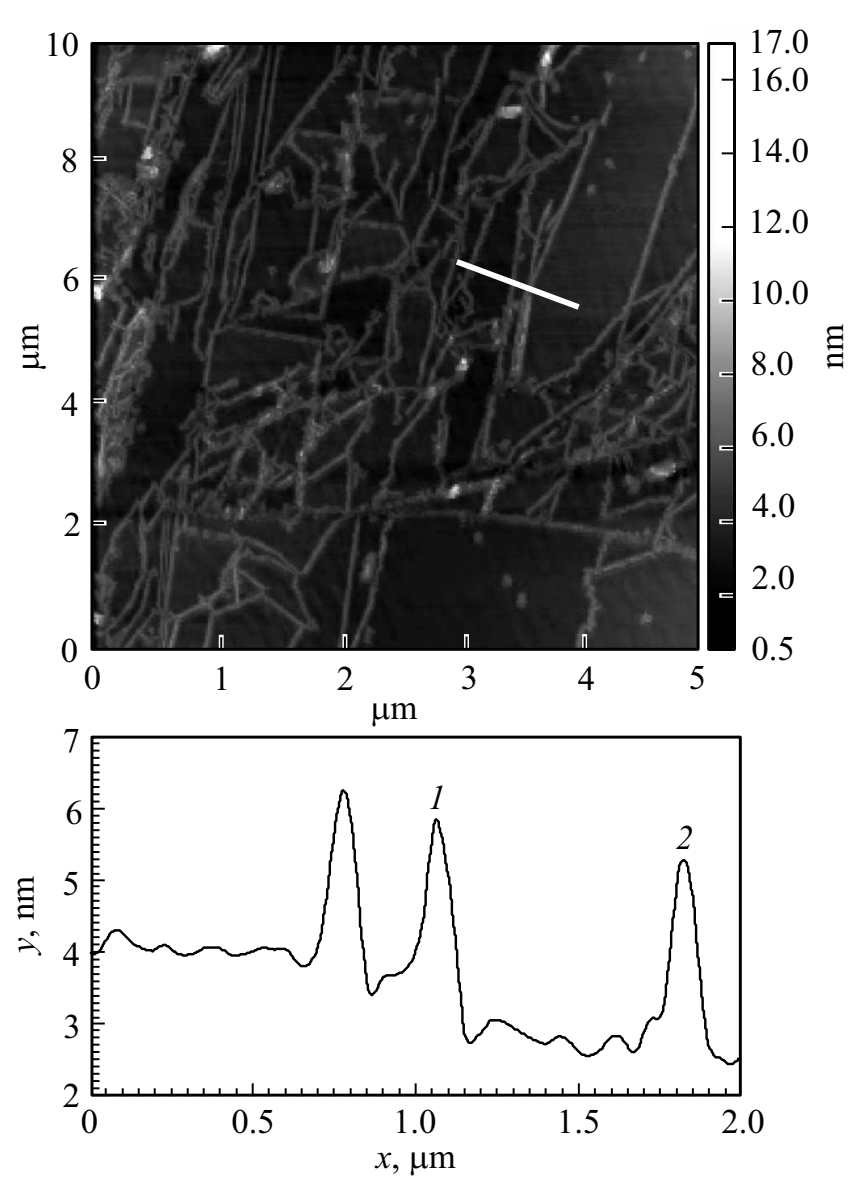

Рис. 4. $a$ - АСМ-изображение образца № $2,10 \times 10 \mu \mathrm{m}$, ниже - сечение АСМ-изображения. Цифры 1 и 2 указывают на кремниевые структуры на границе террас монокристалла и на гладкой поверхности соответственно. Белой линией указано направление сечения.

структуры и ориентированы по границе между террасами, эти границы не являются ключевым элементом, формирующим данную структуру. Вероятно, расположение линий связано с направлением скола подложки.

На рис. 4 изображена поверхность образца № 2 . В отличие от рис. 3 , здесь линии кремния размещены менее упорядоченно, так как поверхность значительно фрагментирована (что согласуется с Оже-спектрами на рис. $2, b)$, а ширина линий больше в 1.5 раза (см. табл. 2). Количество (площадь покрытия) напыленного кремния также больше в 1.5 раза (по сравнению с образцом № 1), то есть, количество линий на единицу площади у двух образцов приблизительно одинаково. Кроме того, на изображении образца № 2 также наблюдаются как линии на границе террас, так и линии на гладкой поверхности (рис. 4, 1 и 2 соответственно).

На рис. 5 изображена поверхность образца № 3. Сравнивая его с образцом № 1, можно заключить, что площадь занимаемой кремниевыми линиями поверхности увеличилась приблизительно в 2 раза (см. табл. 2), в то время как ширина каждой отдельной линии уве- 
личилась в среднем лишь на треть. Это означает, что увеличение количества напыленного кремния приводит не только к увеличению их ширины, но и к появлению новых линий. При этом форма линий (см. рис.5) также изменяется: у них появляются боковые направления роста дендритообразной формы. Кроме того, помимо увеличения средней толщины линий, приблизительно в 1.33 раза увеличивается и их высота.

АСМ-изображение образца № 4 представлено на рис. 6. По сравнению с образцом № 3, площадь занимаемой поверхности ниже, а высота линии незначительно выше (в пределах погрешности), что соответствует уменьшению количества кремния на поверхности при той же толщине напыляемого слоя. Эти данные полностью согласуются с данными ОЭС (рис. 2, $b$, спектры 3 и 4). По всей видимости, при повышении температуры подложки возрастает подвижность атомов кремния на поверхности HOPG, и процесс коалесценции кремния в вышеописанные линейные структуры происходит более активно. Исчезают дендриты, наблюдаемые на рис. 5, и линии становятся более узкими, однако количество линий на единицу площади (отношение ширины линии
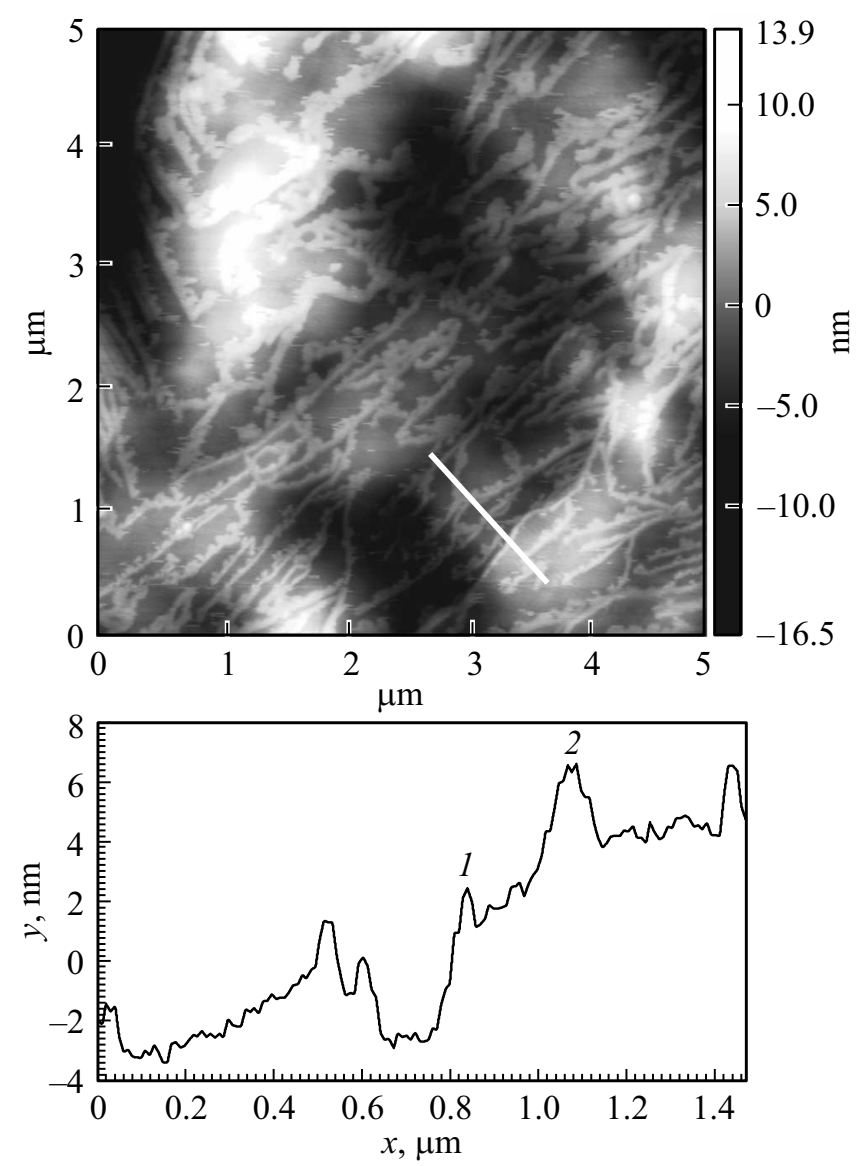

Рис. 5. $a$ - АСМ-изображение образца № $3,5 \times 5 \mu \mathrm{m}$, ниже - сечение АСМ-изображения. Цифры 1 и 2 указывают на кремниевые структуры на границе террас HOPG и на гладкой поверхности соответственно. Белой линией указано направление сечения.
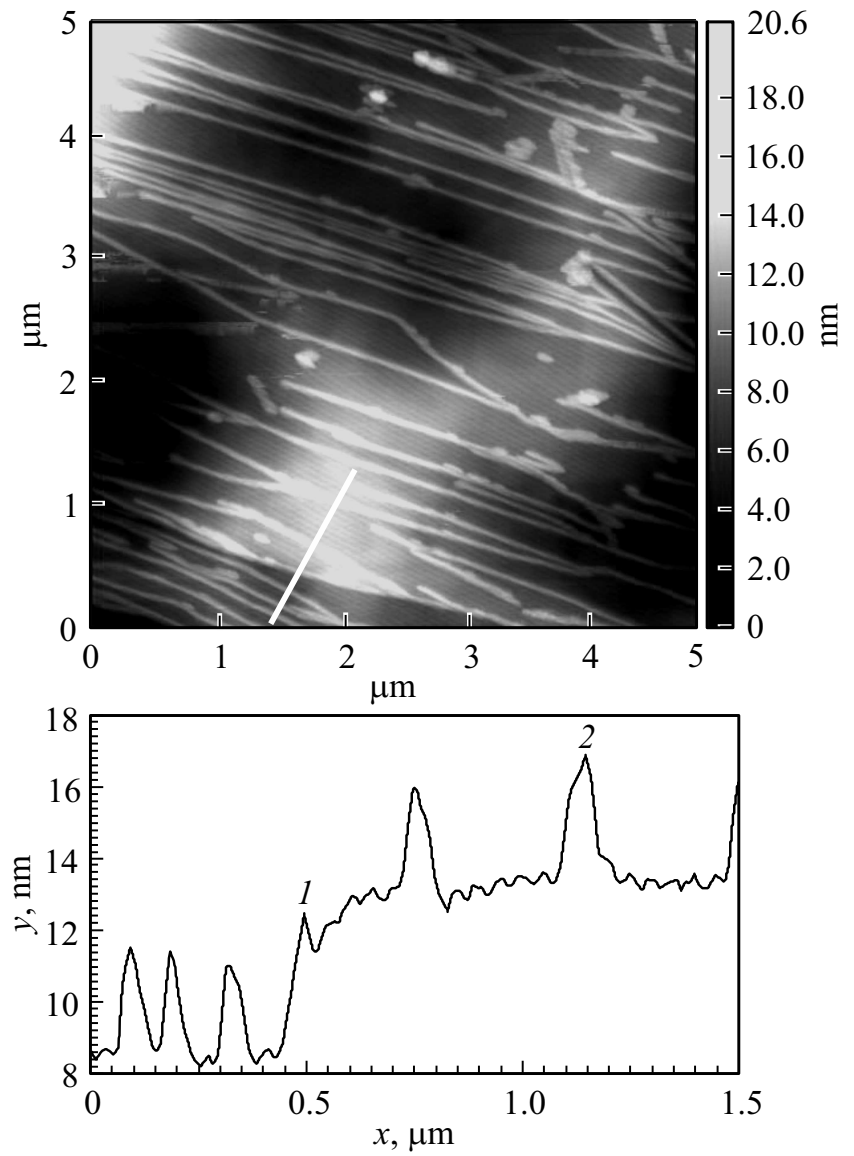

Рис. 6. $a-$ АСМ-изображение образца № $4,5 \times 5 \mu \mathrm{m}$; ниже - сечение АСМ-изображения. Цифры 1 и 2 указывают на кремниевые структуры на границе террас HOPG и на гладкой поверхности соответственно. Белой линией указано направление сечения.

к занимаемой площади) остается таким же, как и для образца без прогрева. Также на этом изображении, как и в случае образца № 1, линии кремния преимущественно имеют одно направление, перпендикулярное направлению скола подложки.

\section{4. Заключение}

В настоящей работе исследовалась возможность формирования упорядоченных кремниевых структур на поверхности графитовых подложек за счет вариации таких параметров синтеза, как температура подложки, толщина напыляемого материала и кристаллическая однородность подложки. В работе показано, что формирование монослойного силицена на подложке НOPG или монокристаллическом графите не представляется достижимым в связи с коалесценцией атомов кремния в линейные структуры с $s p^{3}$-гибридизированными состояниями, причем этот процесс упорядочен и зависит от структуры подложки. При этом все факторы, связанные с химическим взаимодействием кремния с углеродом 
или кислородом, исключены ОЭС-измерениями, а изменение ключевых параметров синтеза не приводит к уменьшению толщины напыляемых структур и соответствующему пропорциональному увеличению занимаемой ими площади.

\section{Финансирование работы}

Исследования проводились на оборудовании ресурсного центра „Физические методы исследования поверхности“ Научного парка и лаборатории Физической электроники кафедры Электроники твердого тела СПбГУ.

\section{Конфликт интересов}

Авторы заявляют, что у них нет конфликта интересов.

\section{Список литературы}

[1] A.H. Castro Neto, F. Guinea, N.M.R. Peres, K.S. Novoselov, A.K. Geim. Rev. Mod. Phys. 81, 109 (2009).

[2] M. Batzill. Surf. Sci. Rep. 67, 3-4, 83 (2012).

[3] O.V. Yazyev. Rep. Prog. Phys. 73, 056501 (2010).

[4] E.V. Zhizhin, A. Varykhalov, A.G. Rybkin, A.A. Rybkina, D.A. Pudikov, D. Marchenko, J. Sánchez-Barriga, I.I. Klimovskikh, G.G. Vladimirov, O. Rader, A.M. Shikin. Carbon 93, 984 (2015).

[5] E.V. Zhizhin, D.A. Pudikov, A.G. Rybkin, A.E. Petukhov, Y.M. Zhukov, A.M. Shikin. Mater. Des. 104, 284 (2016).

[6] Е.В. Жижин, Д.А. Пудиков, А.Г. Рыбкин, П.Г. Ульянов, А.М. Шикин. ФТТ 57, 9, 1839 (2015).

[7] H. Oughaddou, H. Enriquez, M.R. Tchalala, H. Yildirim, A.J. Mayne, A. Bendounan, G. Dujardin, M.A. Ali, A. Kara. Prog. Surf. Sci. 90, 46 (2015).

[8] A. Kara, H. Enriquez, A.P. Seitsonend, L.C. Lew Yan Voone, S. Vizzini, B. Aufrayg, H. Oughaddoub. Surf. Sci. Rep. 67, 1 (2012).

[9] A. Fleurence, R. Friedlein, T. Ozaki, H. Kawai, Y. Wang, Y. Yamada-Takamura. Phys. Rev. Lett. 108, 245501 (2012).

[10] B. Aufray, A. Kara, S. Vizzini, H. Oughaddou, C. Leandri, B. Ealet, G.L. Lay. Appl. Phys. Lett. 96, 183102 (2016).

[11] L. Meng, Y. Wang, L. Zhang, S. Du, R. Wu, L. Li, Y. Zhang, G. Li, H. Zhou, W.A. Hofer, H. Gao. Nano Lett. 13, 2, 685 (2013).

[12] M. Švec, P. Hapala, M. Ondráček, P. Merino, M. Blanco-Rey, P. Mutombo, M. Vondraček, Y. Polyak, V. Cháb, J.A. Martín Gago, P. Jelínek. Phys. Rev. B 89, 201412(R) (2014).

[13] P.M. Sheverdyaeva, S.K. Mahatha, P. Moras, L. Petaccia, G. Fratesi, G. Onida, C. Carbone. ACS Nano 11, 1, 975 (2017).

[14] Д.А. Пудиков, Е.В. Жижин, А.А. Вишнякова, О.Ю. Вилков, Г.Г. Владимиров. ФТТ 59, 12, 2447 (2017).

[15] A. Acun, B. Poelsema, H.J.W. Zandvliet, R. van Gastel. Appl. Phys. Lett. 103, 263119 (2013)

[16] M.D. Crescenzi, I. Berbezier, M. Scarselli, P. Castrucci, M. Abbarchi, A. Ronda, F. Jardali, J. Park, H. Vach. ACS Nano 10, 12, 11163 (2016).
[17] R. Leach. Characterisation of Areal Surface Texture. Springer, Berlin, Heidelberg (2013). C. 15-43.

[18] L.E. Davis, N.C. MacDonald, P.W. Palmberg, G.E. Riach, R.E. Weber. Physical Electronics Division. Perkin-Elmer Corporation (1976). $143 \mathrm{c}$.

[19] A. Zangwill. Physics at surfaces. Cambridge University Press, Cambridge (1988). C. 21.

Редактор К.В. Емцев 